\title{
Monomer Release from Resin Based Dental Materials Cured With LED and Halogen Lights
}

\author{
Asli Topaloglu Ak \\ A. Riza Alpoz \\ Oguz Bayraktarc \\ Fahinur Ertugruld
}

\section{ABSTRACT}

Objectives: To measure the release of TEGDMA and BisGMA from two commercially available composite resins; Filtek Z 250 (3M ESPE, Germany), Leaddent (Leaddent, Germany) and two fissure sealants; Helioseal F (3M ESPE, Germany) Enamel Loc (Premiere Rev, USA) over 1, 3 and 7 days after polymerization with standard quartz-tungsten halogen Coltolux II (QHL) (Coltene Switzerland) and a standard blue light emitting diode Elipar Freelight 2 (3M ESPE, Germany).

Methods: 9 samples of each material were placed in disc shaped specimens in $1 \mathrm{~mm}$ of thickness and $10 \mathrm{~mm}$ in diameter ( $\mathrm{n=36}$ ). Each material was polymerized using LED for $20 \mathrm{~s}(\mathrm{n}=12), 40 \mathrm{~s}(\mathrm{n}=12)$ and halogen for $40 \mathrm{~s}(\mathrm{n}=12)$, respectively. High Performance Liquid Chromatography (HPLC) was used to measure the amount of monomers released over 1, 3 and 7 days. Data was analyzed using one way ANOVA and Bonferroni test for multiple comparisons with a significance level of .05.

Results: LED $20 \mathrm{sec}$ group showed the highest release of monomers at 1, 3 and 7 days in sealant groups. Halogen $40 \mathrm{sec}$ group resulted highest release of monomers for Leaddent at all time intervals $(P<.05)$

Conclusions: Efficiency of the curing unit and applying the recommended curing time of the light activated resin based dental materials is very important to protect the patient from potential hazards of residual monomers. (Eur J Dent 2010;4:34-40)

Key words: BisGMA; TEGDMA; Residual monomer; Composite resin; Fissure sealant.

Research Assistant, Ege University, School of Dentistry, Department of Paediatric Dentistry, Izmir, Turkey.

b Professor, Ege University, School of Dentistry, Department of Paediatric Dentistry, Izmir, Turkey. Associate Professor, Izmir Institute of Technology, Department of Chemical Engineering, Izmir, Turkey.

d Associate Professor, Ege University, School of Dentistry, Department of Paediatric Dentistry, Izmir, Turkey.
Corresponding author: Dr. Asli Topaloglu Ak

Ege University, School of Dentistry, Department of Paediatric Dentistry, Bornova, Izmir, P.K: 35100, Turkey. Phone: +90232388 6431

Fax: + 902323880325

E-mail: aslitopalogludyahoo.com 


\section{INTRODUCTION}

Light activated resin based dental restorative materials are most widely accepted among clinicians for restorations and fissure sealants., Among their advantages, control of contour during restoration, improved color stability, increased polymerization and rapid setting compared to chemical activated materials come primarily. ${ }^{3}$ However, despite these advantages; both chemical and light activated dental materials are under scope for their biological effects and biocompatibility. $^{4-7}$

One of the most common drawbacks of a composite resin and a resin based fissure sealant is the inadequate polymerization which results with high residual monomers. Consequently, this leads to inferior physical properties. ${ }^{8,9}$ Previous studies indicated that, oxygen prevents polymerization of monomer by the formation of an inhibition zone on the surface of a resin in contact with air. ${ }^{10,11}$ Hence, sealant materials have even more potential for leaving uncured resin components since these materials are cured without an occlusal matrix. ${ }^{12}$ These unreacted components may either attach to polymer chain or integrate into host systemically by saliva, mucosal tissue membranes and pulp tissues. This may result with allergic or adverse side effects in both patient and dental staff. ${ }^{13,14}$ The significance of removing the leaching monomers from the oxygen inhibited layer of resin based materials have been documented in the literature. ${ }^{12,15}$

Factors affecting the polymerization of the resins include those, directly related to restorative material and light curing units. In order to achieve the adequate polymerization to overcome the residual monomers, curing units and techniques have been studied by many researches. ${ }^{16,17}$

Halogen lights have been most commonly used devices for the polymerization of resin based dental materials. This low cost technology device have drawbacks such as decline of irradiance over time due to bulb and filter ageing which could lead to inadequate polymerization. ${ }^{18-20}$ Different technologies for light curing resin based materials have been developed to overcome these disadvantages. One such alternative is light emitting diode (LED) which is a highly efficient light source that produces light within a narrow spectral range. LED is very popular among paediatric dentists particularly, since less chair time and an adequate polymeriza- tion is the main goal and there are few studies on the curing performance of different curing units using HPLC (High Performance Liquid Chromatographyl in time related elution of term. ${ }^{21-23}$

The objective of this study was to determine the time related release residual monomers from different brands of commercially available resin based fissure sealants and composite resins polymerized using different curing units with different exposure time.

\section{MATERIALS AND METHODS}

Sample fabrication

Two composite resins, Filtek Z 250 (3M ESPE, Seefeld, Germany) and Lead Dent (Leaddent, Germanyl and two resin based fissure sealants, Helioseal F (Ivoclar Vivadent AG, Liechtenstein, Germany) and Enamel Loc (Premier Dental Products Company, REV, USA) were used in this study. The chemical compositions of these materials are listed in Table 1.

For each resin based dental materials, 9 discshaped specimens $110 \mathrm{~mm}$ diameter and $1 \mathrm{~mm}$ thickness) were prepared using silicone rubber molds $(n=36)$. The molds were placed on flat glass plates on top of acetate strips and then filled with resin based material. The material was covered with an acetate strip and gently pressed with another glass plate against the mold to extrude excess material.

Curing method and exposure time

Halogen light Coltolux II (QHL) (Coltene, Switzerland) and LED Elipar Freelight 2 (3M ESPE, Germanyl were used for the polymerization of the samples. The technical details of halogen light and LED are presented in Table 2. Nine samples of each material were $(n=36)$, polymerized using LED for $20 \mathrm{~s}(\mathrm{n}=12), 40 \mathrm{~s}(\mathrm{n}=12)$ and halogen light for $40 \mathrm{~s}(\mathrm{n}=12)$, respectively. The distance between the light source and sample was standardized by using a $1 \mathrm{~cm}$ glass plate. The light tip was in close contact with the restoration surface during polymerization. All specimens were prepared in a temperature controlled room at $23 \pm 1^{\circ} \mathrm{C}$. Immediately after light-curing, the cover glasses were removed from the mold.

Release studies and HPLC analysis

After curing, samples were immediately submerged in $5 \mathrm{ml}$ of ethanol at $37^{\circ} \mathrm{C}$ for 7 days and 
were analyzed at 1, 3 and 7 days, respectively. BisGMA and TEGDMA released from samples were analyzed by reversed phase HPLC high performance liquid chromatography (HPLC) equipped with a diode array detector. The detection was performed at wavelength of $254 \mathrm{~nm}$. The stationary phase was a C18 LiChrospher 100 analytical column (250x4 mm i.d.) with a particle size of 5 $\mathrm{mm}$ thermostated at $35^{\circ} \mathrm{C}$. The mobile phase was an isocratic solution of $65 \%$ acetonitrile, at a flow rate of $1.5 \mathrm{~mL} \mathrm{~min}{ }^{-1}$. The injection volume was 20 $\mu \mathrm{l}$ and the measurements were performed after 1 , 3 and 7 days and repeated 3 times for all release media. BisGMA and TEGDMA monomers were identified by comparison of their retention times with the corresponding standards. Chromatogram of standard monomer sample is given in Figure 1.

One-way analysis of variance was used to analyze data on the quantity of monomer released by monomer type, time intervals and different light curing methods. Multiple comparisons were analyzed using Bonferroni test. Statistical analysis was conducted at a significance level of $P<.05$.

\section{RESULTS}

Tables 3-6 show the mean amounts of BisGMA and TEGDMA released from Helioseal F, Enamel Loc, Filtek Z 250 and Leaddent samples respectively after 1,3 and 7 days following immersion in ethanol. In Helioseal $F$ group, the release of BisGMA was statistically higher in LED 20 s group compared to LED $40 \mathrm{~s}$ group for all time intervals $(P<.05)$ whereas this difference was significant for TEGDMA only after 3 days, $(P<.05)$. In Enamel Loc group, LED $20 \mathrm{~s}$ released more TEGDMA in com- parison to LED $40 \mathrm{~s}$ after 1 and 3 days $(\mathrm{P}<.05)$. For BisGMA, LED 20 s group released more monomer than LED $40 \mathrm{~s}$ and QTH $40 \mathrm{~s}$ at all time intervals $(P<.05)$

There was no significant difference noted for release of TEGDMA monomer among curing methods at all time intervals in Filtek Z 250 composite resin samples ( $P>$.05). However, there was a significant difference in the release of BisGMA after 3 and 7 days when halogen 40s was compared to LED $40 \mathrm{~s}$ group. LED $40 \mathrm{~s}$ group released less monomer $(\mathrm{P}<.05)$.

In Leaddent composite resin sample group, the release of both TEGDMA and BisGMA were significantly less for LED $40 \mathrm{~s}$ group compared to halogen $40 \mathrm{~s}$ for all time intervals $(P<.05)$. This difference was significant compared to LED 20 s only after 7 days.

\section{DISCUSSION}

It has been shown that various components may be released from resin based dental restorative materials into the oral environment. ${ }^{9}$ These components namely, degradation products, oligomers and residual monomers can affect the biocompatibility of the materials. The amount of residual, unreacted monomer in a resin based dental material has been implicated in causing cytotoxicity and leading to a mechanical degradation in the material itself. Recently it has been also reported that released monomers from dental materials show synthetic eustrogenic activity. ${ }^{10,24}$ Hence researches have focused on the contributing factors to monomer elution from resin based dental materials. Among these factors, chemistry

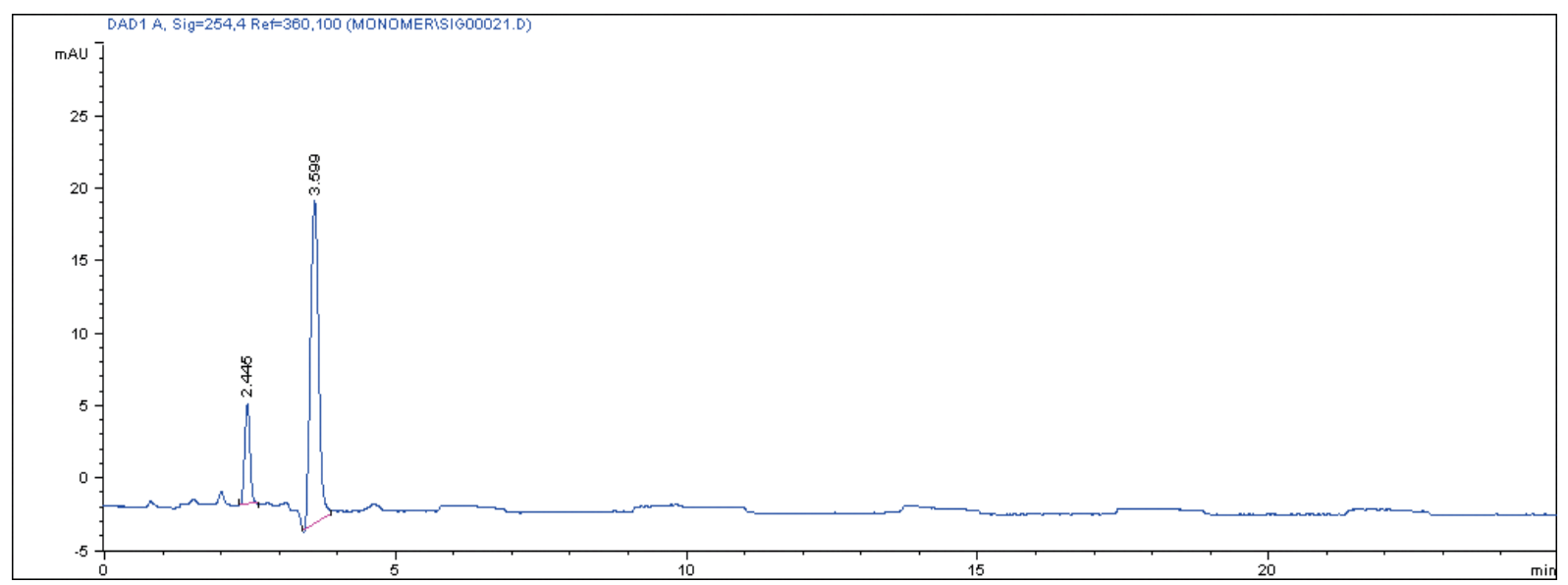

Figure 1. Chromatogram of the standard monomer sample. 
of the solvent, size and chemical nature of released components and extent of polymerization are the most significant ones. ${ }^{8}$

It is well defined that in order to minimize the amount of residual monomer elution, resin based restorative materials have to be polymerized to a high degree. ${ }^{25}$ Yet, it is indicated that a complete monomer conversion is never succeeded and the degree of conversion varies between $35 \%$ and $77 \%{ }^{8,26}$ Consequently, curing source intensity, wavelength, exposure duration, thickness of over- lying material tip to tooth curing distance has been a topic of investigations to determine the optimal conditions for resin polymerization. ${ }^{2}$ It is widely accepted that, an intensity of $300 \mathrm{~mW} / \mathrm{cm}^{2}$ or greater at a wavelength range of $450-500 \mathrm{~nm}$ is required for complete polymerization of a $2 \mathrm{~mm}$ composite resin, ${ }^{27}$ although different intensities and exposure time are suggested by other researchers. ${ }^{28,29}$

Since the introduction of LED devices in restorative dentistry, there has been an increased interest in comparing their ability with regular

Table 1. Chemical composition of resin based dental materials used.

\begin{tabular}{|c|c|c|}
\hline Resin Based Dental Materials & Chemical Composition & Manufacturer \\
\hline Helioseal F & Bis-GMA, TEGDMA,UDMA & Ivoclar Vivadent AG, Liechtenstein, Germany \\
\hline \multirow{4}{*}{ Enamel Loc } & UDMA, TEGDMA, & \\
\hline & Methacrylated phosphoric & Premier Dental \\
\hline & acid esters, & \\
\hline & $\begin{array}{l}\text { 4-methacryloxy } \\
\text { ethyltrimellitic acid }\end{array}$ & Products Company, REV, USA \\
\hline Filtek Z 250 & Bis-GMA, UDMA, Bis-EMA & 3M, ESPE, Seefeld, Germany \\
\hline Leaddent & Bis-GMA, TEGDMA, UDMA & Leadent, Germany \\
\hline
\end{tabular}

Table 2. Technical details of the halogen and LED light-curing units.

\begin{tabular}{llll}
\hline Light Curing Units & Wavelength & Intensity & Manufacturer \\
\hline Coltolux II & $400-515 \mathrm{~nm}$ & $400 \mathrm{~mW} / \mathrm{cm}^{2}$ & (Coltene, Switzerland) \\
LED Elipar Freelight 2 & $430-480 \mathrm{~nm}$ & $1200 \mathrm{~mW} / \mathrm{cm}^{2}$ & (3M ESPE, Germany) \\
\hline
\end{tabular}

Table 3. Mean TEGDMA and BisGMA release (concg/L) from Helioseal F fissure sealant samples in to ethanol after 1,3 and 7 days. $a, b, c, d P<.05$.

\begin{tabular}{lcccccc}
\hline & \multicolumn{3}{c}{ TEGDMA (concg/l) } & \multicolumn{3}{c}{ BisGMA (concg/l) } \\
$\begin{array}{lccccc}\text { Immersion } \\
\text { time (days) }\end{array}$ & LED 20 & LED 40 & QTH 40 & LED 20 & LED 40 & QTH 40 \\
& mean \pm sd & mean \pm sd & mean \pm sd & mean \pm sd & mean $\pm s d ~$ & mean $\pm s d$ \\
\hline 1 & $(n=3)$ & $(n=3)$ & $(n=3)$ & $(n=3)$ & $(n=3)$ & $(n=3)$ \\
\hline 3 & $7.55 \pm 0.32$ & $6.54 \pm 1.0$ & $6.74 \pm 0.66$ & $0.41^{\mathrm{a}} \pm 0.07$ & $0.24^{\mathrm{a}} \pm 0.04$ & $0.3 \pm 0.05$ \\
7 & $9.61^{\mathrm{b}} \pm 0.53$ & $7.54^{\mathrm{b}} \pm 0.84$ & $8.24 \pm 0.7$ & $0.45^{\mathrm{c}} \pm 0.04$ & $0.31^{\mathrm{c}} \pm 0.03$ & $0.36 \pm 0.04$ \\
\hline
\end{tabular}

Table 4. Mean TEGDMA and BisGMA release (concg/L) from Enamel Loc fissure sealant samples in to ethanol after 1,3 and 7 days. a,b,c,d,e,f,g,h $P<.05$.

\begin{tabular}{|c|c|c|c|c|c|c|}
\hline \multirow[b]{2}{*}{$\begin{array}{l}\text { Immersion } \\
\text { time (days) }\end{array}$} & \multicolumn{3}{|c|}{ TEGDMA (concg/l) } & \multicolumn{3}{|c|}{ BisGMA (concg/l) } \\
\hline & $\begin{array}{c}\text { LED } 20 \\
\text { mean } \pm s d \\
(n=3)\end{array}$ & $\begin{array}{l}\text { LED } 40 \\
\text { mean } \pm s d \\
(n=3)\end{array}$ & $\begin{array}{c}\text { QTH } 40 \\
\text { mean } \pm \text { sd } \\
(n=3)\end{array}$ & $\begin{array}{l}\text { LED } 20 \\
\text { mean } \pm s d \\
(n=3)\end{array}$ & $\begin{array}{l}\text { LED } 40 \\
\text { mean } \pm s d \\
(n=3)\end{array}$ & $\begin{array}{c}\text { QTH } 40 \\
\text { mean } \pm s d \\
(n=3)\end{array}$ \\
\hline 1 & $0.26^{a} \pm 0.03$ & $0.11^{a} \pm 0.04$ & $0.19 \pm 0.01$ & $0.27^{b, c} \pm 0.08$ & $0.09^{b} \pm 0.01$ & $0.06^{c} \pm 0.01$ \\
\hline 3 & $0.36^{d} \pm 0.05$ & $0.18^{d} \pm 0.04$ & $0.25 \pm 0.02$ & $0.46^{\mathrm{f}, \mathrm{e}} \pm 0.17$ & $0.15^{\dagger} \pm 0.02$ & $0.1^{e} \pm 0.01$ \\
\hline 7 & $0.43 \pm 0.03$ & $0.42 \pm 0.08$ & $0.39 \pm 0.03$ & $0.55^{\mathrm{g}, \mathrm{h}} \pm 0.11$ & $0.33^{9} \pm 0.06$ & $0.17^{h} \pm 0.03$ \\
\hline
\end{tabular}


halogen lights. ${ }^{30}$ This study used a standard halogen light intensity of $400 \mathrm{~mW} / \mathrm{cm}^{2}$. A2 colorshade was chosen for the composite resins to minimize the effect of colorants on light penetration. ${ }^{31}$ In the present study two composite resins and two fissure sealants were studied after polymerization with different curing units and exposure time at 1,3 and 7 days time intervals. There was no BisGMA in Enamel Loc and there was no TEGDMA in Filtek Z250's chemical compositions based on the information received from the manufacturers. However, all samples showed detectable levels of BisGMA and TEGDMA except for Filtek Z250 which released very small amount of TEGDMA with almost the same value of standard deviations that remained same for all time intervals. This result is line with manufacturer information regarding that Filtek Z250 does not contain TEGDMA as base monomers.

Bis-GMA is an ingredient in many dental resins and pit and fissure sealants. In Enamel Loc group, detection of BisGMA was possible although it was not stated in the chemical formulation. By the time we started our study Enamel Loc was available at the market and was known as a relatively new self etching sealant. However, at the time of the completion of the study, it was discontinued by the manufacturer. It was claimed that heat and cold temperature extremes may cause phase separation in the resin. The detection of BisGMA could be attributed to changes in the chemical composition of the material and high sensitivity of HPLC analysis as well. Pit and fissure sealant materials contain more resin matrix and less filler particles than other dental composite materials which results in containing more monomer.

HPLC analysis is one of the most trustable and commonly used separation method among other techniques. ${ }^{32}$ In the present study HPLC analysis was used to evaluate the monomer release from 2 different composite resins and fissure sealants. Elution of residual monomers from dental materials depends on the chemical composition of leachable substances as well as the chemistry of the solvent. ${ }^{8}$ Tanaka et $a l^{14}$ revealed that, small molecular weight monomers such as TEGDMA could be eluted more than the higher weight molecules, namely BisGMA and UDMA for their faster mobility. In the present study, the amount of TEGDMA was found to be higher than the amount of BisGMA for all dental materials. This could derive from differences in chemical properties and reactive potentials of TEGDMA and BisGMA to different curing methods. ${ }^{33}$

Table 5. Mean TEGDMA and BisGMA release (concg/L) from Filtek Z 250 composite resin samples in to ethanol after 1,3 and 7 days. $a, b \quad P<.05$.

\begin{tabular}{|c|c|c|c|c|c|c|}
\hline \multirow[b]{2}{*}{$\begin{array}{l}\text { Im mersion } \\
\text { time (days) }\end{array}$} & \multicolumn{3}{|c|}{ TEGDMA (concg/l) } & \multicolumn{3}{|c|}{ BisGMA (concg/l) } \\
\hline & $\begin{array}{c}\text { LED } 20 \\
\text { mean } \pm s d \\
(n=3)\end{array}$ & $\begin{array}{c}\text { LED } 40 \\
\text { mean } \pm s d \\
(n=3)\end{array}$ & $\begin{array}{c}\text { QTH } 40 \\
\text { mean } \pm s d \\
(n=3)\end{array}$ & $\begin{array}{c}\text { LED } 20 \\
\text { mean } \pm s d \\
(n=3)\end{array}$ & $\begin{array}{c}\text { LED } 40 \\
\text { mean } \pm s d \\
(n=3)\end{array}$ & $\begin{array}{c}\text { QTH } 40 \\
\text { mean } \pm s d \\
(n=3)\end{array}$ \\
\hline 1 & $0.01 \pm 0.00$ & $0.01 \pm 0.0$ & $0.01 \pm 0.01$ & $0.04 \pm 0.01$ & $0.03 \pm 0.01$ & $0.05 \pm 0.02$ \\
\hline 3 & $0.01 \pm 0.01$ & $0.01 \pm 0.01$ & $0.01 \pm 0.01$ & $0.06 \pm 0.01$ & $0.04^{\mathrm{a}} \pm 0.01$ & $0.07 \mathrm{a} \pm 0.01$ \\
\hline 7 & $0.01 \pm 0.01$ & $0.01 \pm 0.01$ & $0.01 \pm 0.01$ & $0.07 \pm 0.00$ & $0.05^{b} \pm 0.01$ & $0.07^{b} \pm 0.01$ \\
\hline
\end{tabular}

Table 6. Mean TEGDMA and BisGMA release (concg/L) from Leaddent composite resin samples in to ethanol after 1,3 and 7 days. a,b,c,d,e,f,g,h $P<.05$.

\begin{tabular}{|c|c|c|c|c|c|c|}
\hline \multirow[b]{2}{*}{$\begin{array}{l}\text { I m mersion } \\
\text { time (days) }\end{array}$} & \multicolumn{3}{|c|}{ TEGDMA (concg/l) } & \multicolumn{3}{|c|}{ BisGMA (concg/l) } \\
\hline & $\begin{array}{c}\text { LED } 20 \\
\text { mean } \pm s d \\
(n=3)\end{array}$ & $\begin{array}{c}\text { LED } 40 \\
\text { mean } \pm s d \\
(n=3)\end{array}$ & $\begin{array}{c}\text { QTH } 40 \\
\text { mean } \pm s d \\
(n=3)\end{array}$ & $\begin{array}{c}\text { LED } 20 \\
\text { mean } \pm s d \\
(n=3)\end{array}$ & $\begin{array}{c}\text { LED } 40 \\
\text { mean } \pm s d \\
(n=3)\end{array}$ & $\begin{array}{c}\text { QTH } 40 \\
\text { mean } \pm s d \\
(n=3)\end{array}$ \\
\hline 1 & $0.15 \pm 0.05$ & $0.10^{\mathrm{a}} \pm 0.01$ & $0.28^{a} \pm 0.08$ & $0.12 \pm 0.05$ & $0.07^{b} \pm 0.01$ & $0.23^{b} \pm 0.07$ \\
\hline 3 & $0.21 \pm 0.01$ & $0.11^{c} \pm 0.01$ & $0.31^{c} \pm 0.09$ & $0.17 \pm 0.01$ & $0.08^{d} \pm 0.01$ & $0.27^{\mathrm{d}} \pm 0.07$ \\
\hline 7 & $0.23^{e} \pm 0.01$ & $0.12^{f} \pm 0.01$ & $0.43^{e, f} \pm 0.09$ & $0.20^{9} \pm 0.01$ & $0.09^{h} \pm 0.00$ & $0.37^{g, h} \pm 0.09$ \\
\hline
\end{tabular}


The elution values reported in this study are higher than previous studies. 8,23 This is because the specimens were placed into the solvent right after polymerization. This is clinically relevant and corresponds to a period when further curing of material is occurring, which would tend to bind more of the unreacted molecules. It is also indicated that the rate and extent of elution of monomer is greater in organic solvents compared to pure water. However it should be noted that, unreacted monomer leaching in an organic solvent does not imitate the clinical conditions yet presents the potentially leachable portions of dental materials. ${ }^{34}$ In the present study ethanol was used as an organic solvent to measure the elution of BisGMA and TEGDMA from composite resins and fissure sealants sample. Acetonitrile was used as the solvent and mobile phase since BisGMA and TEGDMA are hydrophobic and it has been used in previous studies concerning HPLC analysis of resin restorative materials. ${ }^{35}$

Manufacturers' recommendation for curing time for Helioseal F, Enamel Loc and Filtek Z250 is $20 \mathrm{~s}$ whereas for Leaddent it is $40 \mathrm{~s}$. Based on the differences in polymerization conditions in dental practices, we used different curing units and exposure time. In the present study, 20 and $40 \mathrm{~s}$ for LED unit and $40 \mathrm{~s}$ curing time for halogen light was used for the $1 \mathrm{~mm}$ thickness of tested resin based materials. For the sealant groups, polymerization with LED for $40 \mathrm{~s}$ yielded less monomer elution than the recommended $20 \mathrm{~s}$. For the composite resin groups, recommended $20 \mathrm{~s}$ curing time for Filtek Z250 resulted with same amount of elution compared to $40 \mathrm{~s}$ of curing with LED and halogen light. However, $40 \mathrm{~s}$ of curing with LED eluted less in comparison to halogen $40 \mathrm{~s}$.

\section{CONCLUSIONS}

Monomer release from resin based dental materials is detectable and curing performance of different curing units and exposure time can be detected by HPLC in time related elution of monomers. Therefore, efficiency of the curing unit and applying the recommended curing time of the light activated resin based dental materials is very important to protect the patient from potential hazards of residual monomers.

\section{REFERENCES}

1. Craig RG, editor. Restorative Dental materials, 10 th ed. St. Louis, MO: C.V. Mosby Company; 1997.

2. Rueggeberg FA, Caughman WF, Curtis JW Jr. Effect of light intensity and exposure duration on cure of resin composite. Oper Dent 1994;19:26-32.

3. Burgess JO, De Goes M, Walker R, Ripps AH. An evaluation of four light curing units comparing soft and hard curing. Pract Periodontics Aesthet Dent 1999;11:125-132.

4. Geurtsen W, Spahl W, Leyhausen G. Variability of cytotoxicity and leaching of substances from four light curing pit and fissure sealants. J Biomed Mater Res 1998; 44:73-77.

5. Schedle A, Franz A, Rausch-Fan X, et al. Cytotoxic effects of dental composites, adhesive substances, compomers and cements. Dent Mater 1998;14:429-440.

6. Stanley HR. Effects of dental restorative materials: local and systemic responses reviewed. J Am Dent Assoc 1993; 124:76-80.

7. Mohsen NM, Craig RG, Hanks CT. Cytotoxicity of urethane dimethacrylate composites before and after aging and leaching. J Biomed Mater Res 1998;39:252-260.

8. Ferracane JL. Elution of leachable components from composites. J Oral Rehab 1994;21:441-452.

9. Guertsen W. Substances released from dental resin composites and glass ionomer cements. Eur J Oral Sci 1998;106:687-695.

10. Ruyter IE. Unpolymerized surface layers on sealants. Acta Odontol Scand 1981;39:27-32.

11. Rueggeberg FA, Margeson DH. The effect of oxygen inhibition on an unfilled/filled composdite system. J Dent Res 1990;69:1652-1658.

12. Komurcuoglu E, Olmez S, Vural N. Evaluation of residual monomer elimination methods in three different fissure sealants in vitro. J Oral Rehab 2005;32:116-121.

13. Tarle Z, Meniga A, Knezevic A, Sutalo J, Ristic M, Pichler G. Composite conversion and temperature rinse using a conventional, plasma arc and an experimental blue LED curing unit. J Oral Rehab 2002;29:662-667.

14. Tanaka K, Taira M, Shintani H, Wakasa K. The release of monomeric methyl methacrylate from acrylic appliances in the human mouth; an assay for monomer in saliva. $J$ Dent Res 1988;67:1295-1299.

15. Rueggeberg FA, Dlugokinski M, Ergle JW. Minimizing patients' exposure to uncured components in a dental sealant. J Am Dent Assoc 1999;130:1751-1757.

16. Mc Cabe J, Carrick T. Output from visible light activation units and depth of cure of light activated composites. J Dent Res 1989;68:1534-1539. 
17. Leonard DL, Charlton DG, Roberts HW, Cohen ME. Polymerization efficiency of LED curing lights. J Esthet Restor Dent 2002; 14:286-295.

18. Dunn WJ, Bush AC. A comparison of polymerization by light-emitting diode and halogen based light curing units. $J$ Am Dent Assoc 2002;133:335-341.

19. Hammesfahr PD, O'Connor MT, Wang X. Light curing technology: Past, present and future. Compend Contin Educ Dent 2002;23:18-24.

20. Mills RW, Jandt KD, Ashworth SH. Dental composite depth of cure halogen and blue light emitting diode technology. Br Dent Journal 1999;186:388-391.

21. Okte Z, Villalta P, Garcia-Godoy F, Garcia-Godoy F Jr, Murray $P$. Effect of curing time and light curing systems on the surface hardness of compomers. Oper Dent 2005;30:540545.

22. Nalcacı A, Ulusoy N, Atakol O. Time-based elution of TEGDMA and BisGMA from resin composite cured with LED, QTH and high-intensity QTH lights. Oper Dent 2006;31:197203.

23. Yap AUJ, VTS Han, Soh MS, Siow KS. Elution of leachable components from composites after LED and Halogen light irradiation. Oper Dent 2004;29:448-453.

24. Caughmann WF, Caughmann GB, Shiflett R, Rueggeberg F, Schuster G. Correlation of cytotoxicity, filler loading and curing time of dental composites. Biomaterials 1991;12:737740.

25. Munksgaard EC, Peutzfeld A, Asmussen E. Elution of TEGDMA and BisGMA from a resin and a resin composite cured with halogen or plasma light. Eur J Oral Sci 2000;108:341345.

26. Spahl W, Budzikiewicz H, Guertsen W. Determination of leachable components from four commercial dental composites by gas and liquid chromatography/mass spectrometry. J Dent 1998;26:137-145.

27. Lee SY, Chiu CH, Boghosian A, Greener EH. Radiometric and spectrroradiometric comparison of power outputs of five visible light-curing units. J Dent 1993;21:373-377.

28. Unterbrink GL, Muessner R. Influence of light intensity on two restorative systems. J Dent 1995;23:183-189.

29. Yap AU, Wong NY, Siow KS. Composite cure and shrinkage associated with high intensity curing light. Oper Dent 2003;28:357-364.

30. O'Reilly M, Ray NJ, Mc Connell RJ, Hannigan A. Surface microhardness of a nanofilled resin composite: a comparison of a tungsten halogen and a light-emitting diode light curing unit, in vitro. Eur J Prost Rest Dent 2007;15:146-152.

31. Bayne SC Heymann HO, Swift EJ Jr. Update on dental composite restorations. J Am Dent Assoc 1994;125:687-701.
32. Moharamzadeh K, Van Noort R. Brook IM, Scutt AM. HPLC analysis of components released from dental composites with different resin compositions using different extraction media. J Mat Sci Mater Med 2007;18:133-137.

33. Stansburry JW, Dickens SH. Determination of double bond conversion in dental resins by near infrared spectroscopy. Dent Mat 2001;17:71-79.

34. Caughmann WF, Rueggeberg FA, Curtis JW Jr. Clinical guidelines for photocuring restorative resins. J Am Dent Assoc 1995;126:1280-1286.

35. Noda M, Komatsu H, Sano H. HPLC analysis of dental resin composites components. J Biomed Mater Res 1999;47:374378. 